\title{
Cholinergic Inhibition of Adrenergic Transmission in the Dog Retractor Penis Muscle
}

\author{
Fumihiko KINEKAWA, Seiichi KOMORI and Hidenori OHASHI \\ Department of Pharmacology, Faculty of Agriculture, Gifu University. \\ Yanagido 1-1, Gifu 501-11, Japan
}

Accepted December 1, 1983

\begin{abstract}
Muscarinic, cholinergic depression of adrenergic excitatory transmission was investigated by the microelectrode method in isolated dog retractor penis muscle. Electrical stimulation of the intramural nerves with single or repetitive stimuli elicited adrenergic contractions and excitatory junction potentials (e.j.p.s). The mechanical response and e.j.p. were suppressed by physostigmine $\left(5 \times 10^{-7} \mathrm{~g} /\right.$ $\mathrm{ml}$ ) and carbachol (up to $5 \times 10^{-8} \mathrm{~g} / \mathrm{ml}$ ) without changing the sensitivity of the muscle to noradrenaline and muscle membrane resistance measured by electrotonic potentials. Atropine reversed the drug-induced attenuation of these responses, but atropine itself had no effect on them. Carbachol at $5 \times 10^{-8} \mathrm{~g} / \mathrm{ml}$, where the e.j.p. was blocked, caused a depolarization of the muscle membrane (less than $5 \mathrm{mV}$ ). whereas the same extent of depolarization produced by high $\mathrm{K}$ solution resulted in only a small decrease in e.j.p. amplitude. These results suggest that excitatory adrenergic transmission in the dog retractor penis muscle is depressed prejunctionally by a cholinergic mechanism.
\end{abstract}

Recently, compelling evidence has been accumulated which implicates acetylcholine as the presynaptic inhibitory modulator to peripheral autonomic nerve-effector junctions $(1-3)$ in the vascular bed and visceral organs. The inhibitory action of acetylcholine is mediated through muscarinic receptors. An important part of this evidence rests on the ability of muscarinic receptor-agonists to suppress the mechanical responses of the smooth muscle to nerve stimulation without any change in the sensitivity to the transmitter or to reduce the amount of transmitter in the perfusate following nerve stimulation.

Klinge and Siöstrand (4) described the inhibition by acetylcholine or physostigmine of the adrenergic contractile response of the dog retractor penis muscle to transmural nerve stimulation and its reversal by antimuscarinic drugs. Further data from this laboratory have provided evidence suggesting a reduction of the transmitter release through activation of muscarinic receptors. However, the muscarinic, cholinergic modification of the neuromiuscular transmission has not been investigated by evaluating junction potentials recorded from the smooth muscle.

The aims of this study were to record excitatory junction potentials in response to adrenergic nerve stimulation in the dog retractor penis muscle and to investigate how physostigmine or carbachol may change them. This paper is also concerned with electrical properties of the muscle required to elucidate drug-induced effects on junction potentials.

Some of our results have been communicated to the Japanese Pharmacological Society (5).

\section{Materials and Methods}

Male dogs were anesthetized with sodium pentobarbital (25 mg/ $\mathrm{kg}$ i.v.) and killed by bleeding. A cannula was inserted into a carotid artery to facilitate bleeding. The paired retractor penis muscles were dissected out, and their proximal regions, which were contaminated with striated muscle fibers, were cut away. Segments of the muscle, $15 \mathrm{~mm}$ long, were dissected after 
detatching the adhering tissues under a binocular microscope.

Recording of mechanical responses: The muscle segment was mounted in a $1 \mathrm{ml}$ organ bath in which a pair of platinum ring electrodes for field stimulation of the intramural nerves were embedded. The bathing solution of Tyrode solution was continuously renewed at $4 \mathrm{ml} / \mathrm{min}$ using a roller pump. Field stimulation $(0.5 \mathrm{msec}$ square-wave pulses, $50 \mathrm{~V}$ ) at varied frequencies for 5 or 10 sec was delivered every 2 or 4 min from a stimulator (Nihon Khoden, MZ-3). Changes in tension produced by nerve stimulation or drugs were recorded isotonically with a load of C.5-1.5 g using an isotonic mechanoelectronic transducer (Nihon Khoden, TD112S). In experiments to observe contractile response to drugs, a $20 \mathrm{ml}$ organ bath was used, and the bathing solution was not perfused. The drugs were applied to the muscle segment by iniecting them into the bathing solution in a $0.05 \mathrm{ml}$ volume using a micropipette and removed by replacing the bathing solution with fresh Tyrode solution. The Tyrode solution was maintained at $30 \pm 1{ }^{\circ} \mathrm{C}$, bubbled with air, and of the following composition (mM): $\mathrm{NaCl}, 136.9$; $\mathrm{KCl}, 2.7 ; \mathrm{NaH}_{2} \mathrm{PO}_{4}, 0.4 ; \mathrm{CaCl}_{2}, 1.8 ; \mathrm{MgCl}_{2}$. 2.1: $\mathrm{NaHCO}_{3}, 11.9$ and glucose, 5.6.

Recording of electrical responses: Glass microelectrodes, filled with $3 \mathrm{M} \mathrm{KCl}$ with tip resistances of 40-100 Mohms, were used for intracellular recording of the membrane potential of the smooth muscle cells. The muscle segment was pinned over a small black rubber board and immersed in a $2 \mathrm{ml}$ organ bath. The bathing solution was kept at $35^{\circ} \mathrm{C}$ and perfused at $4 \mathrm{ml} / \mathrm{min}$. Electrical stimulation of the intramural nerves were effected by a pair of $\mathrm{Ag}-\mathrm{AgCl}_{2}$ electrodes (1 $\mathrm{mm}$ in diameter), one of which was insulated with Araldite except for the tip surface, and placed vertically on the surface of the muscle segment in such a way that the tip surface was kept just attached. The other electrode was placed in the bathing solution. Nerve stimulation was made with single pulses (0.5 msec duration, 12-32 V) or repetitive pulses at frequencies from $0.2 \mathrm{~Hz}$ up to $2 \mathrm{~Hz}$. Potential changes were input into an oscilloscope through a preamplifer and photographed on $35 \mathrm{~mm}$ film. The method used to investigate passive electrical properties of the muscle was similar to that described by Abe and Tomita (6).

Drugs: The following drugs were used and concentrations refer to the salt concentrations in the bathing solution: atropine sulfate (Wako), carbamylcholine chloride (Tokyokasei), noradrenaline bitartrate (Wako), phentolamine mesylate (Ciba Geigy), physostigmine salicylate (Sigma) and tetrodotoxin (Sankyo).

\section{Results}

1. Contractile responses to field stimulation: The muscle showed no spontaneous mechanical activity and responded by contractions to field stimulation at $2-5 \mathrm{~Hz}$. The muscle started increasing its tension at 3-5 sec after commencement of field stimulation, reached the peak and returned to the initial level of tension within 2 min after cessation of the stimulation. The contractile response was evoked usually with one peak, but in some preparations with two or more peaks, and was blocked by phentolamine $\left(5 \times 10^{-7} \mathrm{~g} / \mathrm{ml}\right)$ and tetrodotoxin $\left(10^{-7} \mathrm{~g} / \mathrm{ml}\right)$, this confirming that the response was mediated by the transmitter released from adrenergic fibers through activation of alphaadrenoceptors $(4,7,8)$.

Figure 1 shows suppression of the contractile responses by physostigmine $\left(5 \times 10^{-7}\right.$ $\mathrm{g} / \mathrm{ml})$ and its reversal by atropine $\left(5 \times 10^{-8}\right.$ $\mathrm{g} / \mathrm{ml}$ ). Thus, as suggested by earlier workers (4), adrenergic neuromuscular transmission in the dog retractor penis muscle was thought to be suppressed by a muscarinic receptormediated mechanism.

In order to demonstrate simultaneous release of acetylcholine, field stimulation was made at frequencies of around $20 \mathrm{~Hz}$ in the presence of physostigmine $\left(5 \times 10^{-7} \mathrm{~g} / \mathrm{ml}\right)$ and phentolamine $\left(5 \times 10^{-7} \mathrm{~g} / \mathrm{ml}\right)$. A slow but large rise in tension was evoked following the residual adrenergic contraction (Fig. 2), and it was selectively blocked by atropine, indicating a cholinergic response. Therefore, it is very likely that physostigmine-induced depression of the adrenergic contraction is due to indirect action of physostigmine to accumulate acetylcholine released simul- 


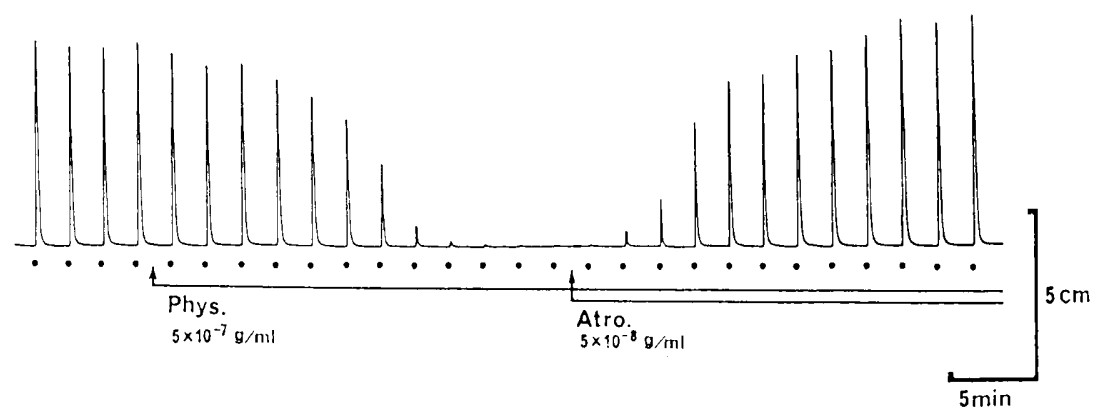

Fig. 1. Inhibitory effect of physostigmine on adrenergic contractile responses to field stimulation. Field stimulation ( $0.5 \mathrm{msec}$ square-wave pulses, $50 \mathrm{~V}$ ) at $5 \mathrm{~Hz}$ for $5 \mathrm{sec}$, delivered every $2 \mathrm{~min}$ (O). Physostigmine, $5 \times 10^{-7} \mathrm{~g} / \mathrm{ml}$, was applied at the arrow ( - Phys.) and then atropine, $5 \times 10^{-8} \mathrm{~g} / \mathrm{ml}$, at the arrow ( $\leftarrow$ Atro.).

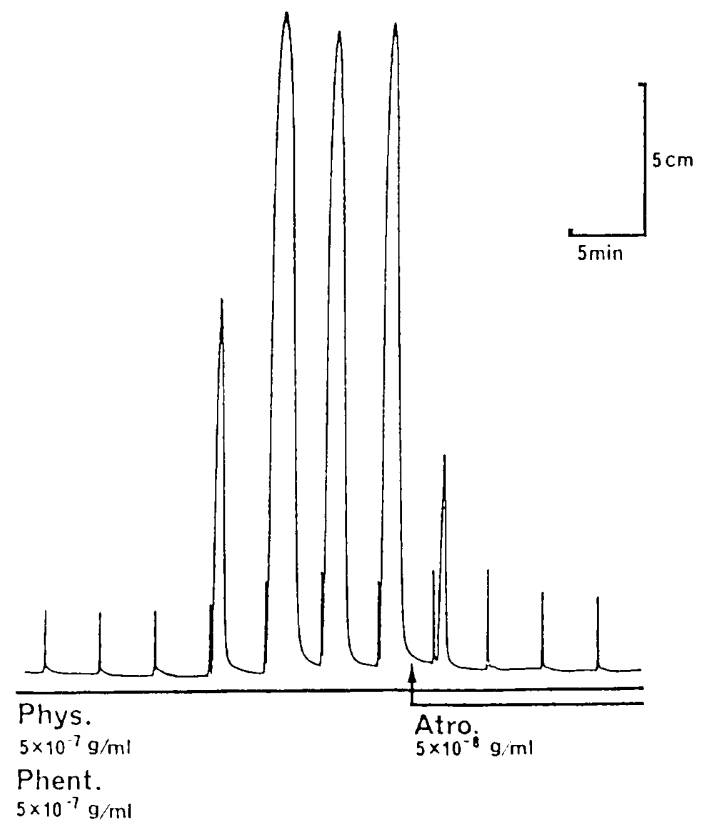

Fig. 2. Cholinergic contractile responses to field stimulation in the presence of physostigmine, $5 \times 10^{-7} \mathrm{~g} / \mathrm{ml}$, and phentolamine, $5 \times 10^{-7} \mathrm{~g} / \mathrm{ml}$. Field stimulation $(0.5 \mathrm{msec}$ square-wave pulses, $50 \mathrm{~V}$ ) at $20 \mathrm{~Hz}$ for $5 \mathrm{sec}$, delivered every $4 \mathrm{~min}$. See slower and larger contractions than the residual adrenergic contractions, blocked by $5 \times 10^{-8} \mathrm{~g} / \mathrm{ml}$ atropine ( $\imath$ Atro.).

taneously with the adrenergic transmitter by field stimulation, and the accumulated acetylcholine inhibits the adrenergic response. If this is the case, carbachol could be expected to reduce the adrenergic responses. Indeed,

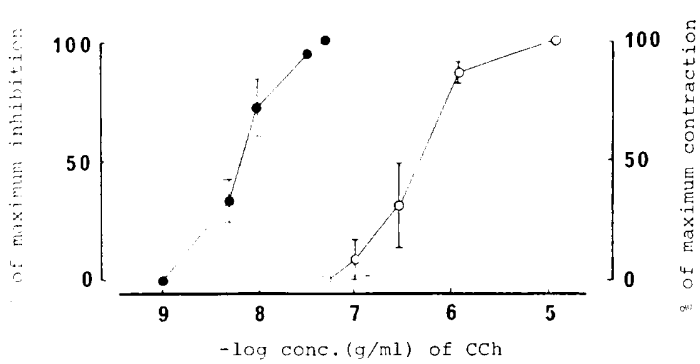

Fig. 3. Dose-dependent inhibitory effect of carbachol on the adrenergic nerve-mediated contractions (-) and its direct action on the smooth muscle $(\mathrm{O}-\mathrm{O})$. Abscissa, -log concentration (g/ $\mathrm{ml}$ ) of carbachol ( $\mathrm{CCh}$ ): ordinate, as a percentage of the maximum inhibition of the nerve-mediated contraction produced by $5 \times 10^{-8} \mathrm{~g} / \mathrm{ml}$ carbachol (left) and as a percentage of the maximum contraction produced by $10^{-5} \mathrm{~g} / \mathrm{ml}$ carbachol itself (right). Each point of the graph is the mean \pm S.E. of 3 experiments. Nerve-mediated contractions were elicited by field stimulation $(0.5 \mathrm{msec}$ square-wave pulses, 50V) at $2 \mathrm{~Hz}$ for $5 \mathrm{sec}$, delivered every $2 \mathrm{~min}$.

carbachol suppressed the adrenergic response in a dose-dependent manner, as shown in Fig. 3. The minimum effective concentration was $2 \times 10^{-9} \mathrm{~g} / \mathrm{ml}$. In a concentration of $5 \times 10^{-8} \mathrm{~g} / \mathrm{ml}$, carbachol abolished completely the adrenergic response, but caused no appreciable change in the resting tone. In concentrations more than $10^{-7} \mathrm{~g} / \mathrm{ml}$, the drug had a contracting effect. Thus, there was a wide gap between effective concentrations to suppress the nerve stimulationmediated response and to cause contraction 
of the muscle (see Fig. 3). The carbacholinduced suppression of the adrenergic response was faster in onset than that produced by physostigmine (Fig. 4), and for carbachol at $5 \times 10^{-8} \mathrm{~g} / \mathrm{ml}$, the time required to reach its peak effect was $2.1 \pm 0.2 \mathrm{~min}$ (mean \pm S.E. mean, $n=7$ ).

Neither carbachol nor physostigmine caused any shift of the dose-response curves for the action of cumulatively-applied noradrenaline in producing contraction of the muscle. The minimum effective concentration (EDmin), 50\% effective concentration (ED50) and minimum concentration to produce the maximum response (EDmax) of noradrenaline were $1.8 \pm 0.4 \times 10^{-8} \mathrm{~g} / \mathrm{ml}$, $2.4 \pm 0.3 \times 10^{-7} \mathrm{~g} / \mathrm{ml}$ and $10^{-5} \mathrm{~g} / \mathrm{ml}$, respectively, in normal solution in five preparations; and these values were $3 \pm 0.2 \times 10^{-8} \mathrm{~g} / \mathrm{ml}$, $1.1 \pm 0.3 \times 10^{-7} \mathrm{~g} / \mathrm{ml}$ and $10^{-5} \mathrm{~g} / \mathrm{ml}$, respectively, in the presence of physostigmine

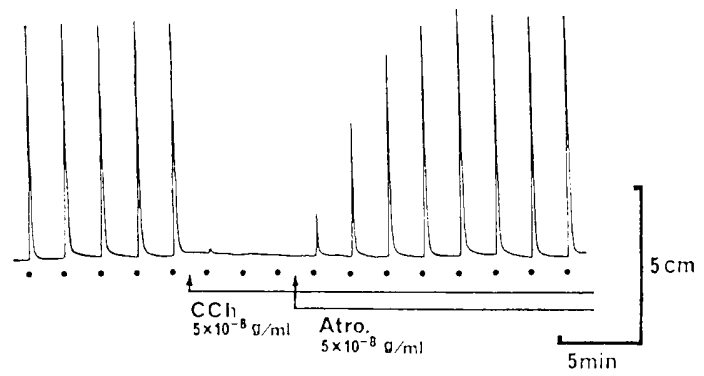

Fig. 4. Inhibitory effect of carbachol on the adrenergic nerve-mediated contraction. Field stimulation ( $0.5 \mathrm{msec}$ square-wave pulses, $50 \mathrm{~V}$ ) at $5 \mathrm{~Hz}$ for $5 \mathrm{sec}$, delivered every $2 \mathrm{~min}(0)$. The response was blocked by $5 \times 10^{-8} \mathrm{~g} / \mathrm{ml}$ carbachol ( $-\mathrm{CCh}$ ) and the effect was readily reversed by $5 \times 10^{-8} \mathrm{~g} / \mathrm{ml}$ atropine ( $\uparrow$ - Atro.) $\left(5 \times 10^{-7} \mathrm{~g} / \mathrm{ml}\right)$ and $1.7 \pm 0.5 \times 10^{-8} \mathrm{~g} / \mathrm{ml}$, $2.2 \pm 0.4 \times 10^{-7} \mathrm{~g} / \mathrm{ml}$ and $10^{-5} \mathrm{~g} / \mathrm{ml}$, respectively, in the presence of carbachol $\left(5 \times 10^{-8} \mathrm{~g} / \mathrm{ml}\right)$, each in three preparations. There was no significant difference between the values before and after either drug. These results indicate that the sensitivity of the muscle to noradrenaline, on adrenergic transmitter, remains unaltered in the presence of these drugs.

2. Adrenergic excitatory junction potentials: Resting membrane potential of the muscle cells was $-59.8 \pm 0.4$ (mean \pm S.E. mean, $n=100$ ). The muscle showed neither spontaneous mechanical activity nor spontaneous electrical activity so that prolonged recording of membrane potential could be made from the same cell. Transmural stimulation with single pulses elicited small and brief depolarizations. The response was blocked by phentolamine $\left(5 \times 10^{-7} \mathrm{~g} / \mathrm{ml}\right)$ or tetrodotoxin $\left(10^{-7} \mathrm{~g} / \mathrm{ml}\right)$, indicating adrenergic excitatory junction potentials (e.j.p.s). E.j.p.s recorded from different cells in one preparation varied in amplitude even when stimulus parameters were kept constant. The amplitude of e.j.p.s was increased with increasing the stimulus intensity, this suggesting multiple innervation to one smooth muscle cell. The latency following the stimulus, time to reach peak amplitude from the onset and time to decay to half the peak amplitude, varied in different preparations and in different cells of one preparation. The mean values for e.j.p.s recorded from 11 cells in different preparatins are given in Table 1.

Repetitive stimulation with short trains of impulses at frequencies from $0.2 \mathrm{~Hz}$ up to $2 \mathrm{~Hz}$ caused a progressive increase in

Table 1. The latency following the stimulus, time to reach peak amplitude from the onset, time to decay to half the peak amplitude, and time constant of the falling phase for the e.j.p.s

\begin{tabular}{lrc}
\hline & Control & Carbachol \\
Latency (msec) & $26.0 \pm 1.6(\mathrm{n}=11)$ & $27.7 \pm 2.9(\mathrm{n}=4)$ \\
Time to peak (msec) & $120.3 \pm 5.3$ & $124.5 \pm 12.2$ \\
Half-decay time (msec) & $326.4 \pm 29.5$ & $352.2 \pm 31.0$ \\
Time constant (msec) & $382.7 \pm 12.6$ & $431.3 \pm 37.9$ \\
\hline
\end{tabular}

Facilitated e.j.p.s in the absence and presence of carbachol, $5 \times 10^{-9} \mathrm{~g} / \mathrm{ml}$, were recorded from respectively 11 cells and 4 cells of different preparations. Each value represents the mean $\pm S$.E. There is no statistically significant difference between each pair (before and after carbachol administration) $(P>0.05)$. 


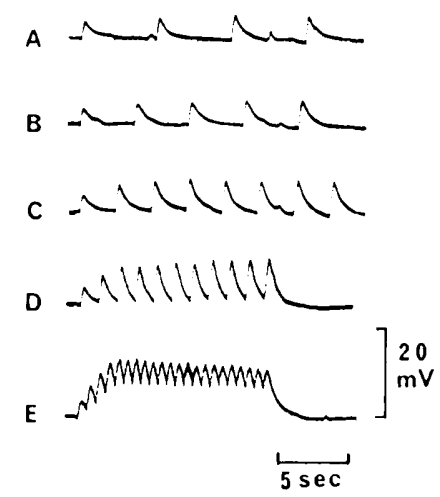

Fig. 5. Excitatory junction potentials (e.j.p.s) recorded from the same cell in response to repetitive stimulation with short trains of impulses $(0.5 \mathrm{msec}$ square-wave pulses, $30 \mathrm{~V}$ ) at varied frequencies. A. $0.2 \mathrm{~Hz} ; \mathrm{B}, 0.3 \mathrm{~Hz} ; \mathrm{C}, 0.5 \mathrm{~Hz} ; \mathrm{D}, 1 \mathrm{~Hz} ; \mathrm{E}, 2 \mathrm{~Hz}$. See spontaneous discharges of e.j.p.s between evoked ones.

amplitude and in rate of rise of the e.j.p. (Fig. 5). The amplitude usually attained a steady-state level at the fifth stimulus. The ratio of the second e.j.p. to the first e.j.p. increased with frequency. At frequencies higher than $0.5 \mathrm{~Hz}$, e.j.p.s resulted in summation in addition to facilitation. The level of the sustained depolarization during repetitive stimulation increased with increasing the stimulus frequency, but the amplitude of e.j.p.s superimposed on the sustained depolarization decreased. On cessation of the stimulation, the membrane potential returned rapidly to the initial level. Action potentials were rarely evoked, even when the depolarization of e.j.p.s reached more than $15 \mathrm{mV}$. However, stimulation at frequencies higher than $2 \mathrm{~Hz}$ invariably elicited contraction which made it difficult to maintain a good impalement of the microelectrode.

In one preparation, e.j.p.s were evoked by paired pulses with varied intervals $(0.5-4.75$ $\mathrm{sec}$ ) and recorded from $20-40$ cells. The amount of facilitation ( $F$ ) was expressed in the form $F=(E 2-E 1) / E 1$, where $E 1$ is the first e.j.p. amplitude and E2 is the second e.j.p. amplitude (9). Figure 6 shows the graph plotting $\log F$ (mean values) against the pulse interval. It can be seen that $F$ declines with increasing pulse interval and could be expressed as two exponential

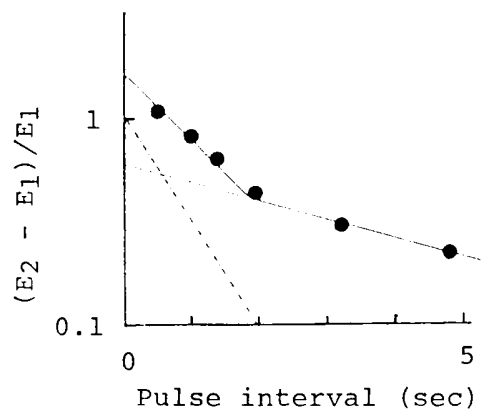

Fig. 6. Facilitation of excitatory junction potentials (e.j.p.s) evoked by paired pulses $(0.5 \mathrm{msec}$ squarewave pulses, $20 \mathrm{~V}$ ) with varied intervals. Abscissa, pulse interval (sec); ordinate, the mean amount of facilitation $(F)$ in the form $F=\left(E_{2}-E_{1}\right) / E_{1}$ on semilogarithmic scale ( $E_{1}$, the first e.j.p. amplitude; $E_{2}$. the second e.j.p. amplitude). The continuous line is given by the equation $\log F=0.62 \cdot \exp ^{-0.23 t}+0.98$. $e x p^{-1.28 t}$, the broken line by $\log F_{f}=0.98 \cdot \exp ^{-1.28 t}$, and the dotted line by $\log F_{s}=0.62 \cdot \exp ^{-0.23 t}$ ( $t$, pulse interval; $F_{f}$, fast component of $F$; $F_{s}$, slow component of F). For further description, see text.

components. Thus, $F=a \cdot \exp ^{-\alpha t}+b \cdot \exp ^{-s t}, t$ is the pulse interval and $\alpha$ and $\beta$ represent rate constants of the two components. From the graph and the equation, $a, b, \alpha$ and $\beta$ are found to be $0.62,0.98,0.23$ and 1.28 , respectively.

During repetitive stimulation, smaller depolarizations than the e.j.p. discharged in the interval between two successive e.j.p.s or in the falling phase of an e.j.p. (Fig. 5). These depolarizations are considered to be spontaneous discharges of e.j.p.s which have been recorded in some adrenergic excitatory junctions (10).

3. Passive electrical properties of the muscle: Electrotonic potentials were recorded at $0.3 \mathrm{~mm}$ from the nearer stimulating plate following application of long current pulses of $800 \mathrm{msec}$ duration at varied intensities through the stimulating plates, and the steady-state amplitude of electrotonic potentials was plotted against the strength of the potential field. The relationship was approximately linear as the membrane was hyperpolarized, but deviated from linearity with depolarization and almost saturated at $20 \mathrm{mV}$ : The membrane behaved as a rectifier. It was almost impossible to evoke an action 
potential by passing outward current. A small action potential could be evoked only in one cell throughout this series of experiments.

As shown in Fig. 7, the steady-state amplitude and rate of growing of electrotonic potentials decreased with the distance from the stimulating partition. The steady-state amplitude declined exponentially with the distance, and there was a linear relationship between the time to reach half of the peak amplitude and the distance. From these properties of the tissue (11), the space

A

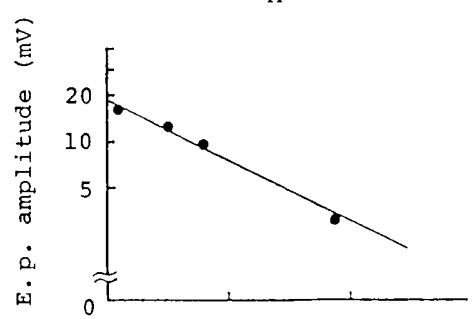

B

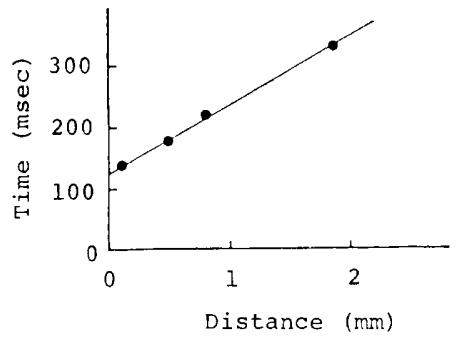

Fig. 7. A, spatial decay of the electrotonic potential (e.p.). Abscissa, distance from the stimulating site; ordinate, size of e.p. on semilogarithmic scale. B, relationship between distance from the stimulating site (abscissa) and the half-time to reach the full size of the e.p. Points were obtained from the same e.p.s as shown in A. constant $(\lambda)$ and membrane time constant $\left(\tau_{\mathrm{m}}\right)$ were obtained, as summarized in Table 2 . The respective mean values of $\lambda$ and $\tau_{\mathrm{m}}$ were $0.9 \pm 0.12 \mathrm{~mm}( \pm$ S.E.) and $199 \pm 32 \mathrm{msec}$ ( \pm S.E.).

4. Time constant of the falling phase of the e.j.p: The e.j.p. reached its peak and then declined roughly in an exponential manner. The mean time to decline to $1 / \mathrm{e}$ of the peak amplitude of e.j.p.s recorded from 11 cells of different preparations was $382.7 \pm 12.6$ msec, which was significantly longer than the membrane time constant ( $199 \pm 32 \mathrm{msec})$. An electrotonic potential and an e.i.p. were recorded from the same cell when current injection and nerve stimulation were effected using the same stimulating plates. The time constant of the falling phase of the e.j.p. was $435 \mathrm{msec}$, being larger than that of the electrotonic potential, $220 \mathrm{msec}$.

5. Effects of noradrenaline on electrotonic potentials and membrane potential: Application of noradrenaline resulted in a decrease in amplitude and time course of electrotonic potentials with membrane depolarization (Fig. 8). The effect on the membrane potential was concentrationdependent (Fig. 9), the minimum effective concentration being less than $10^{-8} \mathrm{~g} / \mathrm{ml}$. Concentrations as high as $10^{-6} \mathrm{~g} / \mathrm{ml}$ achieved a maximal effect of about $15 \mathrm{mV}$. This indicates that the e.j.p. is due to an increase in the permeability of the smooth muscle membrane to some species of ions.

Furthermore, the level of depolarization attained with any concentration of noradrenaline remained almost unaltered in the presence of $5 \times 10^{-8} \mathrm{~g} / \mathrm{ml}$ carbachol.

6. Effects of carbachol on the e.j.p. and electrotonic potential: Carbachol at $5 \times 10^{-9}$ $\mathrm{g} / \mathrm{ml}$ reduced the amplitude of e.j.p.s to

Table 2. Passive electrical properties of the muscle

\begin{tabular}{ccc}
\hline Preparation & $\begin{array}{c}\text { Space constant, } \lambda \\
(\mathrm{mm})\end{array}$ & $\begin{array}{c}\text { Membrane time } \\
\text { constant, } \tau_{\mathrm{m}}(\mathrm{msec})\end{array}$ \\
\hline 1 & 1.10 & 260 \\
2 & 0.67 & 140 \\
3 & 0.65 & 130 \\
4 & 1.16 & 264 \\
\hline
\end{tabular}


A
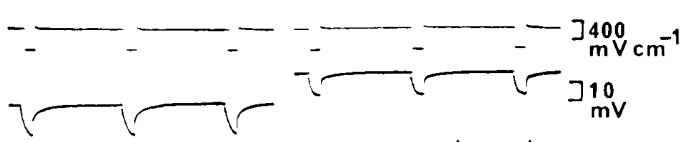

$\underset{5 \mathrm{sec}}{\longleftarrow}$

Fig. 8. Effect of noradrenaline on the electrotonic potential. Upper trace, potential field $(\mathrm{V} / \mathrm{cm})$ : lower trace, intracellular record $(\mathrm{mV})$. A, response to current pulses of $800 \mathrm{msec}$ duration, recorded in normal solution; B. $5 \mathrm{~min}$ after exposure to a solution containing $2.5 \times 10^{-7} \mathrm{~g} / \mathrm{ml}$ noradrenaline.

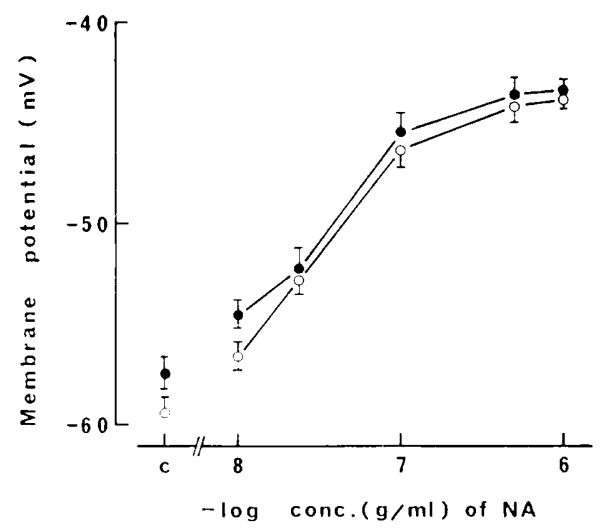

Fig. 9. Effect of noradrenaline on the membrane potential in normal solution and in the presence of carbachol. Abscissa, - $\log$ concentration $(\mathrm{g} / \mathrm{ml})$ of noradrenaline: ordinate, membrane potential. Each point represents the mean of membrane potentials measured before (c) and $5 \mathrm{~min}$ after exposure to noradrenaline in 50 cells of 8 different preparations in normal solution $(\bigcirc-\bigcirc)$ and in the presence of $5 \times 10^{-8} \mathrm{~g} / \mathrm{ml}$ carbachol $(-)$ ). Vertical bars show S.E. of means. There is no statistically significant difference between each pair in normal and carbachol solutions.

$77.2 \pm 2.1 \%$ of the control $(n=6)$, but the time course of e.j.p.s, frequency of spontaneous discharges of e.j.p.s and resting membrane potential remained almost unchanged (see Table 1). When the drug concentration was raised to $5 \times 10^{-8} \mathrm{~g} / \mathrm{ml}$, e.j.p.s were markedly suppressed or abolished, and the membrane was depolarized by less than $5 \mathrm{mV}$ (Fig. 10). To clarify the effect on the membrane potential, records from 4 cells in which the microelectrode was maintained with good impalement in the same cell throughout the

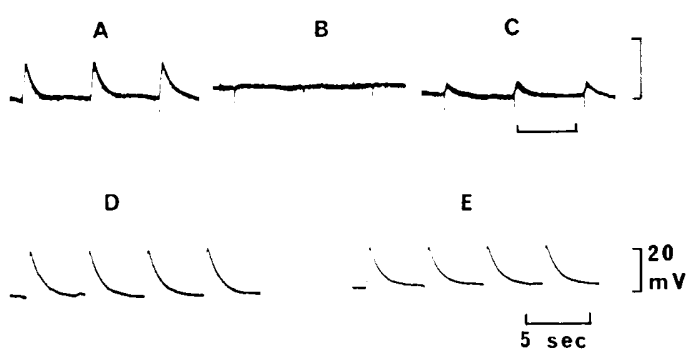

Fig. 10. Effect of carbachol on the excitatory junction potential (e.j.p.). A. e.j.p.s in response to transmural stimulation $(0.5 \mathrm{msec}$ square-wave pulses, $30 \mathrm{~V}$ ) at $0.2 \mathrm{~Hz}$, recorded in normal solution: B. $5 \mathrm{~min}$ after exposure to a solution containing $5 \times 10^{-8} \mathrm{~g} / \mathrm{ml}$ carbachol; $\mathrm{C}, 15 \mathrm{~min}$ after readmission of normal solution: D, e.j.p.s recorded in normal solution: $E, 5$ min after exposure to high $\mathrm{K}$ solution (12.5 mM). A, B and C, records from the same cell. $D$ and $E$, records from the same cell in another preparation.

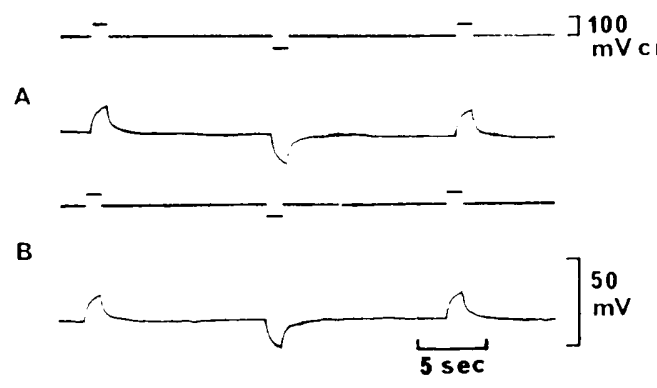

Fig. 11. Failure of carbachol to alter the electrotonic potential. Upper trace, potential field $(\mathrm{mV} / \mathrm{cm})$ : lower trace, iritracellular record $(\mathrm{mV})$. A, the electrotonic potentials in response to current pulses of 800 msec duration, recorded in normal solution: B. $5 \mathrm{~min}$ after exposure to a solution containing $5 \times 10^{-8} \mathrm{~g} / \mathrm{ml}$ carbachol.

period before and after application of carbachol $\left(5 \times 10^{-8} \mathrm{~g} / \mathrm{ml}\right)$ were pooled to estimate the maximum change in membrane potential. The mean of estimated values was $3.3 \pm 1.1 \mathrm{mV}$. When the membrane was depolarized to the same extent as carbacholinduced depolarization by increasing the external $\mathrm{K}$ concentration to $12.5 \mathrm{mM}$, e.j.p.s were still elicited with slightly decreased amplitudes. Carbachol at $5 \times 10^{-8} \mathrm{~g} / \mathrm{ml}$ caused no change in the electrotonic potential (Fig. 11), suggesting no change in the membrane 
resistance. Similar results for the e.j.p. and electrotonic potential were obtained with physostigmine $\left(5 \times 10^{-7} \mathrm{~g} / \mathrm{ml}\right)$, although the onset of the effect was slower than with carbachol. Physostigmine had no effect on the membrane potential. The effects of both carbachol and physostigmine on the e.j.p. and carbachol-induced depolarization were readily abolished by atropine. Atropine alone had no detectable effect on the e.j.p.s.

7. Effect of carbachol on facilitation of e.j.p.s: Facilitation of e.j.p.s elicited by repetitive stimulation could be expressed as two exponential components (see above), and $2 \mathrm{sec}$ or more after commencement of nerve stimulation, it was found to be determined by the slow component $\left(F_{s}\right), F_{s}=a \cdot\left(\exp ^{\alpha t}-1\right)^{-1}$ $\left(1-\exp ^{-\alpha \mathrm{T}}\right)$, where $T$ is time after commencement of stimulation, and $t$ is the pulse interval (sec). Now, the amplitude of subsequent e.j.p.s is given by $1+F_{s}$. Using the

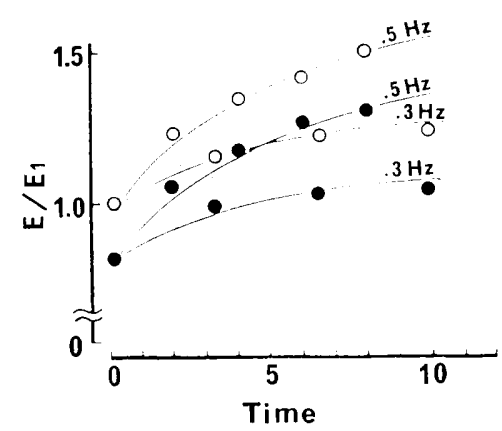

Fig. 12. Effect of carbachol on facilitation of the excitatory junction potentials elicited by transmural stimulation at 0.3 and $0.5 \mathrm{~Hz}$. Abscissa, time (sec) after commencement of a train of pulses $(0.5 \mathrm{msec}$ square-wave pulses, $20-30 \mathrm{~V}$ ); ordinate, the ratio of the amplitude of an e.j.p. (E) to the amplitude of the first e.j.p. $\left(E_{1}\right)$ in the train. Assuming that the time course of decay of facilitation of the e.j.p.s is determined by the slow component obtained from the graph in Fig. 6, the growth of e.j.p.s in a train $\left(E / E_{1}\right)$ is described by the equation $E / E_{1}=0.62$. $\left(\exp ^{0.23 t}-1\right)^{-1}\left(1-\exp ^{0.23 T}\right)$, where $t$ is the interval between successive pulses and $T$ is time (sec) after commencement of the stimulus train. The lines in the graph show the theoretical curves drawn by this equation. Each point represents the mean of several measurements for the e.j.p.s recorded in normal solution (O) and in the presence of $5 \times 10^{-9} \mathrm{~g} / \mathrm{ml}$ carbachol values for a and $\alpha$ obtained above, the curve of $\left(1+F_{s}\right)$ can be calculated at a given stimulus frequency. Figure 12 shows the theoretical curves for e.j.p.s evoked at 0.3 and $0.5 \mathrm{~Hz}$ with points estimated from e.j.p.s recorded from several cells before and in the presence of carbachol $\left(5 \times 10^{-9} \mathrm{~g} / \mathrm{ml}\right)$. The drug reduced the first e.j.p. amplitude to $77 \%$ of the control; however, the points, regardless of the presence of the drug, were distributed close to the theoretical line, suggesting no effect of carbachol on the facilitation process.

\section{Discussion}

Earlier workers $(4,7)$ found that the adrenergic contractile response of the dog retractor penis muscle to field stimulation is suppressed by acetylcholine and physostigmine, and these effects are readily reversed by antimuscarinic drugs. These findings were confirmed and extended to the adrenergic e.j.p. in the present experiments. The effective concentrations for e.j.p. attenuation were in the range for suppression of the contractile response, where these drugs themselves did not change the tension and sensitivity of the muscle to exogenously applied noradrenaline.

Theoretically, the e.j.p. amplitude (E) is expressed by the relation $E=R_{m}\left(E_{t}-E_{m}\right)$ / $\left(\Delta R_{m}+R_{m}\right)$, where $R_{m}$ is the membrane resistance: $\Delta \mathrm{R}_{\mathrm{m}}$, the change in $\mathrm{R}_{\mathrm{m}}$ produced by the transmitter; $E_{t}$, the equilibrium potential for the transmitter; and $E_{m}$, the resting membrane potential $(12,13)$. It could be assumed that there was little change in $E_{t}$ throughout the effect of carbachol at $5 \times 10^{-8} \mathrm{~g} / \mathrm{ml}$ or lower concentrations since the level of noradrenaline-induced depolarization was not changed with the drug at $5 \times 10^{-8} \mathrm{~g} / \mathrm{ml}$ (Fig. 9). Therefore, this equation suggests that $E$ could be affected by the membrane potential or membrane resistance prior to the action of the transmitter. Carbachol, when used at $5 \times 10^{-8} \mathrm{~g} / \mathrm{ml}$, caused no detectable change in the membrane resistance, as measured by electrotonic potentials, but produced a small depolarization of the membrane. However, it should be noted that whereas total abolition of the e.j.p.s was produced by this concentration of carbachol, this was not the case after the same extent of membrane depolarization 
produced by increasing the external $\mathrm{K}$ concentration. This means that most of the attenuation of e.j.p. ainplitude produced by carbachol cannot be achieved through the observed change in membrane potential. Since the response to the transmitter is dependent upon the concentration at the site where it acts, another factor to be considered is the amount of transmitter release. Klinge and Sjöstrand (4) found that the nerve stimulation-induced output of tritium from the muscle preloaded with tritiated noradrenaline was consistentiy decreased by physostigmine, and the effect was counteracted with scopolamine. They interpreted this as evidence indicating reduction of transmitter release from adrenergic nerve endings by a muscarinic receptor-mediated mechanism. A!l of these findings are in keeping with the view that transmission between adrenergic nerves and smooth muscle cells in the dog retractor penis muscle may be depressed through a muscarinic, prejunctional mechanism, as suggested in other peripheral adrenergic nerve-effector junctions (see Introduction). The calculated line for facilitation resembles closely the experimental data of e.j.p.s evoked by repetitive stimulation at 0.3 and $0.5 \mathrm{~Hz}$, suggesting that the cholinergic depressant mechanism may have no effect on the process of facilitation, but show constant suppressive effect on successive e.j.p.s evoked by repetitive stimuli. No effect of carbachol on the latency of the fully facilitated e.j.p. and on the frequency of spontaneous discharges of e.j.p.s could be detected. It is, therefore, unlikely that the depression of e.j.p. amplitude by the cholinergic mechanism is due to retardation of propagation of nerve impulses or depolarization of the adrenergic nerve terminals.

It is clear that field stimulation leads to release of acetylcholine since cholinergic contractions were elicited in the preparations pretreated with physostigmine. However, atropine alone produced no appreciable increase in amplitude of the e.j.p.s, and the time required to produce the maximal effect by physostigmine was fairly constant and longer than that by carbachol. These results indicate that under the present experimental conditions, the muscarinic process is present but not operating in the absence of physostigmine, probably because acetylcholine is released in insufficient amounts to switch on the mechanism. However, this does not necessarily mean that the acetylcholinemediated control system is not functioning under physiological conditions. This system seems to be triggered when cholinergic fibers are stimulated at higher frequencies and release a larger amount of acetylcholine.

It has been inferred from evidence, derived mainly from a pharmacological analysis of the responses to nerve stimulation, that relaxation of the muscle produced by stimulating the parasympathetic fibers is mediated by a non-cholinergic substance $(4,8)$. The presumed transmitter substance remains unknown. An inhibitory substance has been extracted from the bovine retractor penis muscle and shown to mimic the responses produced by nerve stimulation in the dog retractor penis muscle (14-16). In the present experiments, stimulation of the intramural nerves did not elicit any measurable hyperpolarization even after the e.j.p. had been blocked by phentolamine or carbachol. Probably this might result from release of the presumed transmitter in insufficient amounts, the transmitter-induced increase in the membrane permeability to ions whose distribution is dependent on the membrane potential, or the equilibrium potential close to the resting membrane potential. Assuming that stimulation of the parasympathetic fibers release the unknown transmitter as well as acetylcholine, a sudden relaxation of the retractor penis muscle may be produced to cause erection of the penis in two ways, one to depress the e.j.p. through activation by acetylcholine of the muscarinic inhibitory mechanism and the second to relax the smooth muscle through direct action of the unknown transmitter. In most subprimate animals, a sudden relaxation of the retractor penis muscle has been regarded as an important event in erection.

The adrenergic e.j.p. is mediated by alphaadrenoceptors since it was blocked by phentolamine, an alpha-adrenoceptorblocking agent. The fact that as the stimulus intensity was increased, the e.j.p. amplitude 
increased shows that one muscle cell (or functional bundle) is under influence from more than one nerve fiber: multiple innervation. The larger time constant of the falling phase of the e.j.p. than the membrane time constant suggests that the falling phase may be determined by sustained action of the transmitter, but not by passive electrical properties of the membrane. The relatively short latency of the e.j.p. and spontaneous discharges of e.j.p.s suggest that the gap between the adrenergic nerve endings and smooth muscle cells may be not so different from that in other male genital organs of different animals (10).

\section{References}

1 Langer, S.Z.: Presynaptic receptors and their role in the regulation of transmitter release. Br. J. Pharmacol. 60, 481-497 (1977)

2 Starke, K.: Presynaptic receptors. Annu. Rev. Pharmacol. Toxicol. 21, 7-30 (1981)

3 Vizi, E.S.: Presynaptic modulation of neurochemical transmission. Prog. Neurobiol. 12, 181-290 (1979)

4 Klinge, E. and Sjöstrand, N.O.: Suppression of the excitatory adrenergic neurotransmission; a possible role of cholinergic nerves in the retractor penis muscle. Acta Physiol. Scand. 100. 368-376 (1977)

5 Kinekawa, F., Komori, S. and Ohashi, H.: Cholinergic inhibition of adrenergic transmission in the dog retractor penis muscle. Japan. J. Pharmacol. 33. Supp. 190P (1983)

6 Abe, Y. and Tomita, T.: Cable properties of smooth muscle. J. Physiol. (Lond.) 196, 87-100 (1968)

7 Klinge, E. and Sjöstrand, N.O.: Contraction and relaxation of the retractor penis muscle and the penile artery of the bull. Acta Physiol. Scand. Supp. 420, 1-81 (1974)

8 Luduena, F.P. and Grigas, E.O.: Pharmacological study of autonomic innervation of dog retractor penis. Am. J. Physiol. 210, 435-444 (1966)

9 Mallart, A. and Martin, A.R.: An analysis of facilitation of transmitter release at the neuromuscular junction of the frog. J. Physiol. (Lond.) 193, 679-694 (1967)

10 Holman, M.E.: Junction potentials in smooth muscle. In Smooth Muscle, Edited by Bülbring, E., Brading, A.F., Jones, A.W. and Tomita, T., p. 244-288, Edward Arnold Press, London (1970)

11 Tomita, T.: Electrical properties of mammalian smooth muscle. In Smooth Muscle, Edited by Bülbring, E., Brading. A.F., Jones, A.W. and Tomita, T., p. 198-247. Edward Arnold Press, London (1970)

12 Bennett, M.R.: Autonomic neuromuscular transmission. Cambridge University Press, Cambridge (1972)

13 Ginsborg, B.L.: Ion movements in functional transmission. Pharmacol. Rev. 19, 289-316 (1967)

14 Ambache, N., Killick, S.W. and Zar, M.A.: Extraction from ox retractor penis of an inhibitory substance which mimics its atropine-resistant neurogenic relaxation. Br. J. Pharmacol. 54, 409-410 (1975)

15 Gillespie, J.S. and Martin, W.: A smooth muscle inhibitory material from the bovine retractor penis and rat anococcygeus muscle. J. Physiol. (Lond.) 309, 55-64 (1980)

16 Gillespie, J.S., Hunter, J.C. and Martin, W.: Some physical and chemical properties of the smooth muscle inhibitory factor in extracts of the bovine retractor penis muscle. J. Physiol. (Lond.) 315, 111-125 (1981) 